\title{
Blog como ferramenta educacional: contribuições para o processo interdisciplinar de educação em saúde
}

\section{Blog as an educational tool: contributions to the interdisciplinary health education process}

\section{Blog como herramienta educativa: contribuciones para el proceso interdisciplinario de la educación para la salud}

Ana Caroline Leite de Aguiar ${ }^{1, a}$

anacarolaguiar@gmail.com | http://orcid.org/0000-0001-9564-5626

José Maria Ximenes Guimarães ${ }^{1, b}$

jose.ximenes@uece.br|http://orcid.org/ooo0-0002-5682-6106

Heraldo Simões Ferreira ${ }^{1, b}$

heraldo.simoes@uece.br | http://orcid.org/0000-0003-1999-7982

Karen Taís Cavalcanti de Almeida ${ }^{1, a}$

karentais.a@gmail.com | http://orcid.org/ooo0-0002-8605-889X

Tatyanne Ferreira Sales Ribeiro ${ }^{1, a}$

tatyannesales@hotmail.com | http://orcid.org/0000-0001-6306-2477.

Tatiane Mota de Anchieta ${ }^{1, c}$

mottanutri2014@gmail.com | http://orcid.org/oooo-0001-62844717

Maria do Socorro da Silva Carneiro ${ }^{1, d}$

socorrinhacarneiro@hotmail.com | http://orcid.org/0000-0002-3960-590X

Bruno Correia da Silva ${ }^{2, e}$

bruno.silva.ifce.edu@gmail.com | http://orcid.org/0000-0002-4479-6042

\footnotetext{
${ }^{1}$ Universidade Estadual do Ceará. Fortaleza, CE, Brasil.

${ }^{2}$ Instituto Federal do Ceará. Fortaleza, CE, Brasil.

a Mestrado em Ensino na Saúde pela Universidade Estadual do Ceará.

b Doutorado em Saúde Coletiva pela Universidade Estadual do Ceará.

c Graduação em Nutrição pelo Centro Universitário Estácio do Ceará.

d Especialização em Saúde da Familia pela Universidade Estadual do Ceará.

e Mestrado em Ciência da Computação pela Universidade Federal de Pernambuco.
}

\section{Resumo}

A sociedade tecnológica digital demanda sujeitos e saberes que cooperem mutuamente para resolver problemas complexos neste mundo de acesso quase imediato à informação. Nesse contexto, docentes e discentes do mestrado em Ensino na Saúde, de uma universidade pública, e do curso Técnico em Redes de Computadores, de um instituto federal, ambos cearenses, criaram o blog Saúde na Era Digital, objetivando 
educação em saúde para o público em geral. A interação virtual nele registrada foi submetida à análise de conteúdo e emergiram três eixos temáticos: uso equilibrado/apropriado das tecnologias de informação e comunicação (TIC); benefícios dessas tecnologias para a saúde; e seus prejuízos. Especificam-se aspectos positivos da experiência: variados recursos educativos no blog; rompimento dos obstáculos tempo/espaço; ambiente cooperativo de aprendizagem virtual; blog para aprendizagem; e ganho comunitário de educação em saúde pela integração graduação-pós-graduação-docência. Registra-se também a dificuldade de alguns usuários no manuseio dessas TIC que, pela experiência, se recomendam para práticas educativas atuais, contextualizadas e interdisciplinares.

Palavras-chave: Tecnologia da informação; Tecnologia educacional; Internet; Educação em saúde; Comunicação em saúde; Gestão da informação em saúde; Comunicação interdisciplinar.

\section{Abstract}

The technological and digital society requires people and knowledges together for mutual co-operation, so that to solve complex problems in a world where the access to information is nearly immediate. In this context, professors and students at a public university in the master's degree course called Ensino na Saúde (the learning about health), and others in the Técnico em Redes de Computadores (technical expert in computer networks) course at a federal institute, both in the state of Ceará, Brazil, published the blog Saúde na Era Digital (health in the digital era), aiming the health education for the general public. The interaction with visitors comments was submitted to the content analysis and three thematic axes emerged: balanced/ appropriate use of information and communication technology (ICT); its benefits to health; and its damage. The positive aspects of the experience were specified: different educational resources used by the blog; overcoming obstacle of time-space; learning cooperative environment; blog for learning; and community gain in health education from the integration graduate-postgraduate-teaching. A difficulty of some people to handle these ICT was observed. ICT are recommended for current, contextualized and interdisciplinary educational practices.

Keywords: Information technology; Educational technology; Internet; Health education; Health communication; Health information management; Interdisciplinary communication.

\section{Resumen}

La sociedad tecnológica y digital necesita personas y conocimientos cooperando entre sí para resolver problemas complejos en este mundo de acceso casi instantáneo a las informaciones. Así, profesores y estudiantes del curso de maestría Ensino na Saúde (enseñanza en salud), en una universidad pública, y del curso Técnico em Redes de Computadores (técnico en redes de computadoras), de un instituto federal, los dos en el estado de Ceará, Brasil, crearon el blog Saúde na Era Digital (salud en la era digital), con el objetivo de educación en salud dirigida al público general. La interacción virtual ha sido sometida al análisis de contenido y tres ejes temáticos surgieron: uso equilibrado/apropiado de tecnologías de la información y la comunicación (TIC); sus beneficios a la salud; sus daños. Fueron especificados aspectos positivos de la experiencia: diversos recursos educativos en el blog; superación de las barreras tempo/espacio; ambiente de cooperación para aprendizaje virtual; blog para aprendizaje; y ganancia de la comunidad en educación en salud por medio de la integración graduación-postgrado-enseñanza. Algunos usuários tuvieron dificuldad en manejar las TIC. Ellas son recomendadas para prácticas educativas actuales, contextualizadas y interdisciplinarias.

Palavras clave: Tecnología de la información; Tecnología educacional; Internet; Educación en salud; Comunicación en salud; Gestión de la información en salud; Comunicación interdisciplinaria. 
Contribuição dos autores:

Concepção e desenho do estudo: todos os autores

Aquisição, análise ou interpretação dos dados: todos os autores

Redação do manuscrito: Ana Caroline Leite de Aguiar

Revisão crítica do conteúdo intelectual: José Maria Ximenes Guimarães e Ana Caroline Leite de Aguiar

Declaração de conflito de interesses: Este trabalho não apresenta conflito de interesses.

Fontes de financiamento: não houve.

Considerações éticas: não há

Agradecimento/Contribuições adicionais: -

Histórico do artigo: Submetido: 01.maio.2017 | Aceito: 12.mar.2018 | Publicado: 29.jun.2018

Apresentação anterior: não há.

Licença CC BY-NC atribuição não comercial. Com essa licença é permitido acessar, baixar (download), copiar, imprimir, compartilhar, reutilizar e distribuir os artigos, desde que para uso não comercial e com a citação da fonte, conferindo os devidos créditos de autoria e menção à Reciis. Nesses casos, nenhuma permissão é necessária por parte dos autores ou dos editores.

\section{Introdução}

O acelerado desenvolvimento científico e tecnológico, com disseminação potencializada pelo advento da internet, mais largamente implementado no Brasil desde o início da década de 1990르, tem reorganizado as relações sociais e, nesse âmbito, reconfigurado os processos de ensino-aprendizagem, o que implica consequências para a construção dos conhecimentos. Entre estas, uma maior complexidade dos problemas a serem solucionados e, portanto, a necessidade de uma ampliação da capacidade analítica, educativa e resolutiva de profissionais ${ }^{2}$, que poderá ser facilitada pela comunicação e integração de saberes e áreas de atuação diversos.

Com efeito, a contemporaneidade demanda profissionais competentes, considerando-se as dimensões técnica, humana, sociopolítica e ética, e capazes de agir individual e coletivamente em variadas situações ${ }^{3-4}$, com desenvolvimento de novas competências face ao avanço tecnológico e científico, já que o acesso à informação vem sendo ampliado e democratizado no contexto da chamada era digital.

Nesse cenário, a internet constitui importante facilitadora desse avanço e da difusão de informações, uma vez que alcança grande parte da população nos mais variados segmentos etários, sociais, econômicos, intelectuais e outros. Essa realidade impõe que também ocorra reconfiguração da relação entre profissional do setor de saúde e usuário, em que seja considerada sua dimensão tecnológica e digital, na oferta e na busca de cuidado, com seus possíveis impactos na promoção da saúde, nos tratamentos e até mesmo em processos de adoecimento.

Isso pode explicar por que a ampla divulgação de informações de saúde tem sido tema de interesse universal nos ambientes virtuais ${ }^{5}$. Para além dessa disseminação informativa, tais ambientes podem se configurar veículos de educação em saúde, reconhecida como base para se desenvolverem prevenção e promoção de saúde, além de contribuir para a formação de sujeitos conscientes de seus direitos, de sua própria saúde e do poder de decisão sobre ela, assim como da corresponsabilização pela saúde da comunidade à qual pertencem. Por outro lado, as ações de educação em saúde, no Brasil, caracterizam-se pela limitação do público-alvo 
e do espaço real das unidades de saúde, de modo que, usualmente, as práticas educativas tradicionais se restringem em abrangência ${ }^{6}$.

$\mathrm{Na}$ perspectiva de responder a essa problemática, com ações desde a formação dos profissionais de saúde, as Diretrizes Curriculares Nacionais (DCNs) atuais preconizam a incorporação das tecnologias de informação e comunicação (TIC) no processo de ensino-aprendizagem no ensino superior ${ }^{7-9}$, guardando-se as singularidades de realidades em relação ao público docente e discente envolvido, região, finalidade, etc. ${ }^{10}$.

Especificamente, na formação na área da saúde, tem-se discutido enfaticamente uma melhor preparação, com mudanças curriculares e metodológicas, para se atenderem demandas sociais cada vez mais complexas ${ }^{7,11-14}$, que se afinam à amplitude do conceito de saúde que se considera atualmente ${ }^{15}$. Conceito que migrou de um estado de ausência de doenças para abranger âmbitos vários da vida, como o biológico, o psicológico, o social e o espiritual, em coerência com a complexidade do ser humano, público-alvo de quem se propõe a atuar como um profissional de saúde.

Para tanto, é recomendável o desenvolvimento de práticas interdisciplinares de saúde, conforme estabelecido nas Diretrizes Curriculares Nacionais ${ }^{4}$, uma vez que viabilizam o encontro e a interação de saberes diferenciados, os quais, em conjunto, tendem a se aproximar de forma mais eficaz da complexa dinâmica saúde-doença. A compreensão dessa integração de saberes estende-se, ainda, à inclusão de distintos atores educacionais em suas necessárias relações - docentes, discentes, usuários, profissionais de saúde - com vistas à qualificação do Sistema Único de Saúde (SUS) ${ }^{16}$.

Frente ao exposto, reconhece-se que as tecnologias de informação e comunicação têm o potencial de mediar e facilitar o desenvolvimento de processos interdisciplinares na área de saúde ${ }^{4}$. Assim, suas diversas ferramentas (vídeos, áudios, imagens, animações, simulações, hipertextos e outras) potencializam o estudo e a análise coletiva de casos, além de colaborar para uma aproximação virtual de estudantes, pesquisadores e profissionais de diversas áreas de saber e lugares do mundo.

Não obstante, são, ainda, reconhecidas dificuldades por parte de alguns discentes e docentes no manuseio das TIC virtuais ${ }^{4}$. Diante disso, a ampliação da interdisciplinaridade com o envolvimento de outras ciências, como a ciência da computação, para enfrentamento/resolução de problemas de saúde parece uma alternativa viável e demandada, pois os problemas atuais principais são sistêmicos. Logo, para sua melhor compreensão e resolução, não são suficientes os saberes e metodologias fragmentados, ainda, presentes, significativamente, nas formações acadêmicas ${ }^{17}$.

De modo complementar, Severino ${ }^{18}$ assevera que os objetos, no mundo, existem em conexões, em rede, formando uma totalidade, que é complexa, já que esses objetos-parte não interagem de modo mecânico, mas dinâmico, compondo e recompondo significações nessa interação. Dessa maneira, isolando-se esses objetos em ciências diversas, habitualmente, eles se separam de sua unidade no todo, e a abordagem de um saber, dadas as suas especificidades, é sempre limitada, de forma que nenhuma consegue esgotar o conteúdo significativo de um objeto, mesmo que se o isole e aprofunde. Todavia, ainda como reflete o autor, não é o caso de, simplesmente, justapor as ciências. É uma interdisciplinaridade real que poderá recompor uma totalidade complexa, tendo em vista a dinamicidade e multiplicidade de significados.

Com base na premissa de que a construção da interdisciplinaridade pode ser facilitada e potencializada pelas TIC, é possível estender o uso dessas tecnologias, também, para oferecer à população uma educação em saúde de qualidade, de acesso ampliado, com recursos diversos para os variados estilos de aprendizagem ${ }^{19}$, sob o prisma de desenvolver a autonomia do aprendiz, a quem é possibilitado gerir seu tempo, ritmo, cooperações e preferências de aprendizagem na utilização desses recursos. Entre essas ferramentas, destaca-se o blog como reconhecido recurso de aprendizagem virtual ${ }^{20}$.

Nesse sentido, tem-se por objetivos, aqui, descrever e analisar o blog como tecnologia potencializadora da interdisciplinaridade no desenvolvimento da educação em saúde em ambientes virtuais. 


\section{Relato da experiência}

Apostando no uso das TIC, particularmente, do blog, como potencializador da interdisciplinaridade e, com esta, de uma educação em saúde em ambiente virtual, operacionalizou-se uma integração entre a disciplina Tecnologias da Informação e Comunicação aplicadas ao Ensino na Saúde, ministrada no Mestrado Profissional Ensino na Saúde (CMEPES), de uma universidade pública, e a disciplina Introdução à Computação, do curso Técnico em Redes de Computadores de um instituto federal, ambos situados no Ceará.

No mestrado supracitado, voltado para a formação e o desenvolvimento docente na saúde, a disciplina de Tecnologias da Informação e Comunicação aplicadas ao Ensino, com 45 horas-aula, tem por objetivo promover a compreensão teórico-conceitual e fomentar o uso das TIC como ferramentas que favorecem a inovação pedagógica mediante a construção de ambientes virtuais de ensino-aprendizagem, valorizando a flexibilidade, interatividade, cooperação e autonomia do educando, confluindo para um modelo de aprendizagem construtivista. Prima-se, portanto, pelo deslocamento do centro desse processo do professor para o aluno, considerado protagonista do ensino-aprendizagem, superando-se a lógica tradicional do ensino enciclopédico.

$\mathrm{Na}$ perspectiva de promover articulação teórico-prática, bem como integração ensino-serviço, a disciplina propõe, como dimensão avaliativa, a construção de blog, voltado para mediar processos de educação em saúde, levando em consideração a inserção e a experiência dos mestrandos nos serviços de saúde e/ou programas educacionais em saúde. Desse modo, espera-se o desenvolvimento de competências e habilidades para a operacionalização de TIC na construção de ambientes virtuais, que se configurem como estratégias para concretizar propostas de educação a distância pautadas no construtivismo ${ }^{21}$. Para tanto, foram formados grupos com até cinco mestrandos, a quem cabia selecionar um tema relevante no campo do ensino relativo à saúde.

Durante a busca de apoio de técnicos em tecnologia da informação para o desenvolvimento do blog, constatouse a oferta da disciplina Introdução à Computação no primeiro semestre do curso técnico mencionado acima, que traz em seu programa de unidade didática (PUD) o desenvolvimento da competência de uso da internet, com suas diversas ferramentas, linguagens e potencialização de seus benefícios e alcance social.

Assim, diante da escolha do tema saúde na era digital para o blog, dada a atualidade e relevância do assunto, observada cientificamente ${ }^{2,5,7}$ e por meio da massificação de TIC virtuais que trabalham conteúdos de saúde, as mestrandas fizeram contato institucional com o curso Técnico em Rede de Computadores do Instituto Federal de Educação Ciência e Tecnologia do Ceará (IFCE), pela facilidade de acesso à instituição e pelo interesse e importância comuns do tema, tanto na graduação quanto na pós-graduação aqui referidas. O contato objetivou, por conseguinte, potencializar e ampliar a experiência educacional do blog e, a partir dessa intermediação, o professor da disciplina Introdução à Computação prontificou-se a integrar-se, com seus alunos, à proposta sugerida.

A integração centrou-se, então, na criação e manuseio de um blog intitulado Saúde na Era Digital, com fins de fomentar discussões/processos de educação em saúde por meio de TIC virtuais, como aplicativos, redes sociais, jogos eletrônicos etc.

Destarte, cinco mestrandas, de categorias profissionais diversas (enfermagem, psicologia, terapia ocupacional e nutrição), criaram o blog, selecionaram e elaboraram materiais para postagens relativos à temática, e os estudantes e professor de computação contribuíram com a ferramenta relativa a aspectos técnicos de acessibilidade, domínio na internet, viabilização de interação virtual com o público visitante.

As interações entre graduandos e pós-graduandos, discentes e docentes, para efetivação e aprimoramento constante do blog também foram possíveis por TIC virtual: chats agendados por meio da plataforma Moodle, cujos cadastros e acessos dos envolvidos foram oportunizados pelo professor de computação. 
A divulgação do blog coube às mestrandas e aos estudantes da graduação, e ocorreu também prioritariamente por TIC virtuais: redes sociais, como Facebook e Instagram, aplicativos, como Whatsapp, e e-mails, uma vez que se destina ao público em geral, sem restrições, incluídos até os próprios graduandos envolvidos, que passaram a ler os conteúdos de saúde da TIC e, como visitantes, a comentar, perguntar, opinar no próprio blog.

Dessa interação, potencializada pela própria ferramenta virtual, foram surgindo discussões relevantes, com propostas de orientações mais contextualizadas e ampliadas acerca do blog Saúde na Era Digital. Considerando-se diversos estilos de aprendizagem, em uma perspectiva andragógica ${ }^{19}$, o blog foi diversificado com espaços para comentários e seção de 'fale conosco', quiz, charges, vídeos, áudios e textos oriundos de fontes reconhecidamente científicas. Tais recursos distribuíram-se nas seguintes seções: apresentação, primeiras reflexões, aplicativos, jogos eletrônicos, atendimentos informatizados e redes sociais.

Como disparador do assunto saúde na era digital, foco do blog, foi elaborado um texto pelas suas criadoras, elucidando o cenário tecnológico atual, uma definição ampliada de saúde e possibilidades de subtemas a serem explorados como pertinentes à temática maior e fundamentados nas reflexões iniciais provocadas textualmente.

Foi realizada, então, uma enquete sobre a abordagem desses subtemas e, com base nos comentários encontrados nas respostas do público, foram definidas as seções seguintes do blog. Cabe ressaltar que estas foram pensadas e construídas também com base em uma perspectiva interdisciplinar, de modo que, em cada uma, além de contribuições específicas de cada categoria profissional em relação ao assunto, havia o desenvolvimento da temática em sua relação com o conceito multidimensional de saúde, abordado pela interlocução entre enfermagem, psicologia, terapia ocupacional e nutrição, áreas das criadoras da ferramenta, como mencionado anteriormente.

Após um mês de manutenção virtual do blog, ele contava com 613 acessos, a maioria identificada como de graduandos (cursos e cidades variadas) e trabalhadores da área de saúde (de diversas formações e segmentos), em um processo de interatividade permanente, que se concretizou não só no registro de visitas às distintas seções, mas também na participação em quiz e comentários sobre os diversificados temas expostos no blog.

No final da disciplina do mestrado, cada grupo apresentou um relato da experiência, evidenciando os impactos da atividade na sua formação e na prática docente em saúde, os recursos de interação e cooperação operacionalizados, além dos aspectos relacionados ao alcance do blog na comunidade, com base nos registros de acesso e nos comentários dos visitantes.

Com a finalidade de se analisar o blog como tecnologia potencializadora da interdisciplinaridade, tendose em conta as repercussões na educação em saúde, procedeu-se a análise de conteúdo ${ }^{22}$, tomando-se como substrato os comentários dos visitantes. Nesse sentido, na pré-análise, foi realizada a compilação e a organização de todas as informações dos comentários registrados nas diferentes seções do blog. Em seguida, foi realizada uma leitura exaustiva, que permitiu a classificação dos dados por meio da identificação de núcleos de sentido. Após se submeterem as unidades de registro aos critérios de homogeneidade, exclusividade e representatividade, foram estruturados os seguintes eixos temáticos: uso equilibrado e apropriado das TIC; benefícios das TIC para a saúde; e prejuízos das TIC para a saúde (Figura 1). 


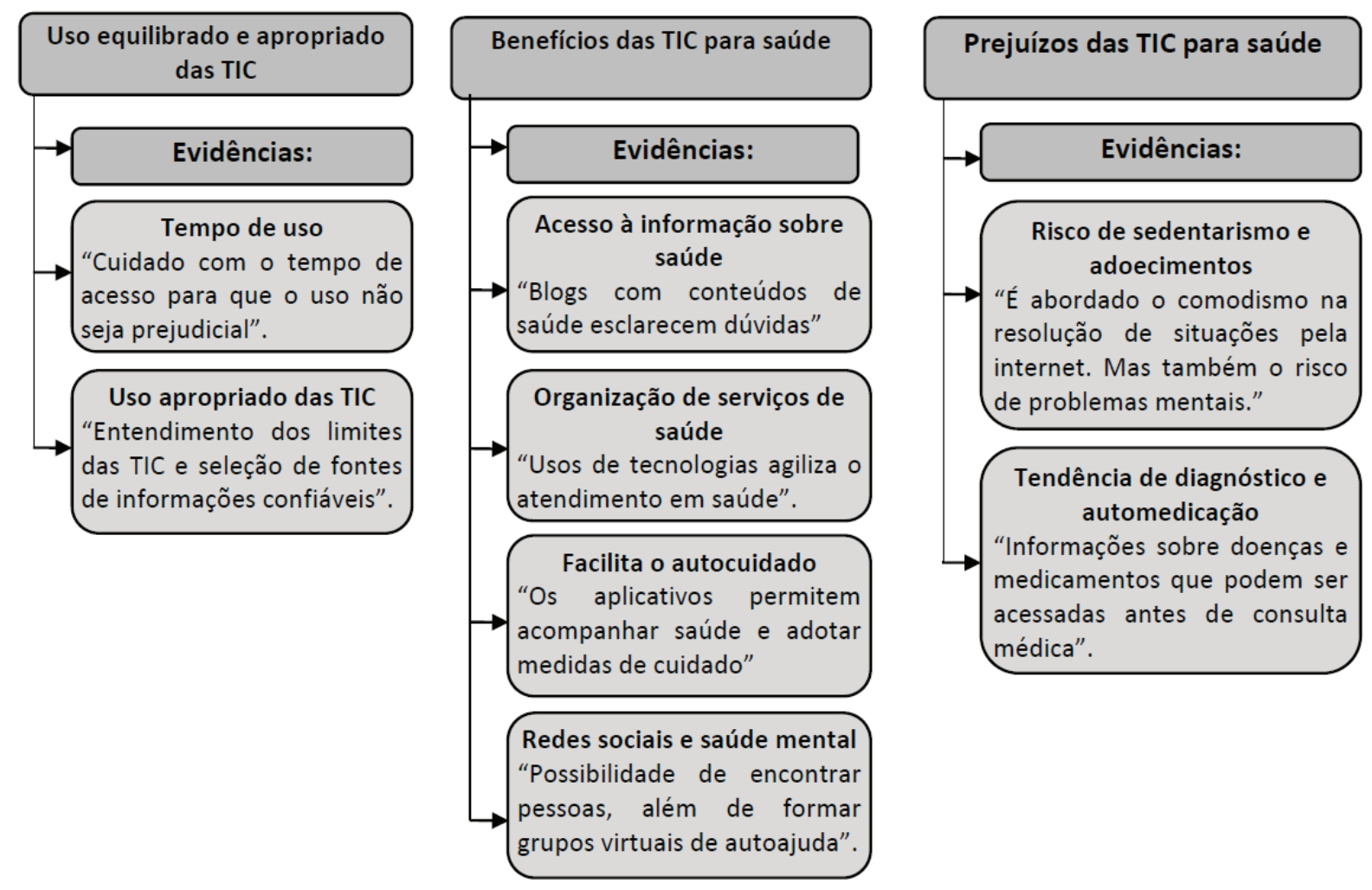

Figura 1 - Fluxograma demonstrativo do processo da análise de conteúdo Fonte: Os autores (2018).

\section{Resultados e discussão}

De início, evidenciou-se que diversos comentários no blog convergiram para a conformação do primeiro eixo temático, o uso equilibrado e apropriado das TIC, em que se alertava a necessidade de equacionamento do tempo destinado ao uso dessas tecnologias no cotidiano, a fim de se evitarem excessos, que podem ser prejudiciais à saúde. Defendeu-se, ainda, o argumento de que o uso apropriado das TIC requisita a adoção de critérios relacionados à confiabilidade da fonte de informações, sobretudo quando se busca adquirir conhecimentos ligados ao processo saúde-doença. Adverte-se, contudo, que o uso excessivo das TIC pode ter efeito negativo na vida do indivíduo, expresso, principalmente, no embotamento/desligamento da vida não virtual. Bauman ${ }^{23}$ corrobora essa reflexão, ao elucidar a liquidez das relações atuais, porquanto efêmeras, muitas vezes, sustentadas pela aceleração das comunicações virtuais.

No que se refere aos benefícios das TIC para a saúde, foram apontados quatro: facilidade do acesso à informação; contribuição das TIC para a organização dos serviços de saúde; as TIC podem auxiliar as práticas de autocuidado em saúde; e as redes sociais, especificamente, podem contribuir para a saúde mental. De modo geral, assinalou-se que o acesso às TIC, principalmente via internet, democratizou o acesso à informação. Assim, são mais facilmente encontradas informações sobre doenças e tratamentos, e ofertas de ações e serviços de saúde, o que acaba direcionando a procura de cuidados.

No âmbito dos serviços de saúde, foi apontado que a incorporação das TIC na organização dos processos de trabalho, particularmente, na informatização do atendimento, reduz a burocracia e otimiza o tempo, conferindo maior qualidade ao atendimento, pois facilita o acesso da equipe interdisciplinar às informações dos usuários, em especial, quando registradas em prontuário eletrônico, o que contribui para minimizar a fragmentação das práticas de cuidado, conforme registrado nos comentários.

Reconhece-se, ainda, a existência de aplicativos que podem ser usados para monitoramento de condições de saúde, porque subsidiam o desenvolvimento de práticas de autocuidado. Desse modo, os visitantes do 
blog listaram aqueles avaliados como mais acessíveis e de fácil manuseio relativos à nutrição (NutraBem, Water your Body, Prato Saudável e outros), à doação de sangue (Blooder), à prevenção de doenças (Antimosquito), a dados de saúde individuais para emergências (Socorro). Os jogos eletrônicos, como o Pokémon Go, de fácil acesso a usuários de diversas idades, foram indicados como auxiliares no combate ao sedentarismo, visto que exigem movimentações/caminhadas dos jogadores na captura de Pokémon.

Ademais, as redes sociais também emergiram como benefícios das TIC para a saúde, posto que foram definidas como relevantes espaços de promoção da saúde mental, pois possibilitam o contato com pessoas queridas e distantes fisicamente, bem como podem ser disparadoras de relacionamentos afetivos entre pessoas que se conhecem por essa via. Além disso, permitem a formação de grupos virtuais que promovem autoajuda em situações especificas de saúde. Todavia, se assevera a importância do uso de configurações nas redes sociais que assegurem ao usuário o controle da exposição virtual e a privacidade relativa, como os mecanismos de proteção da imagem pessoal e de uso de dados privativos.

Autores diversos ${ }^{24-26}$ registram benefícios das TIC, inclusive, para processos de educação permanente entre os trabalhadores da área de saúde. Ademais, observa-se que ganhos para a saúde, como os aqui descritos, mais vinculados a possibilidades de educação em saúde para a comunidade, têm sido uma realidade, tanto que se vislumbram iniciativas de formações específicas para profissionais dessa área a partir da gestão de informações científicas e tecnológicas ${ }^{27}$.

No terceiro eixo temático, prejuízos das TIC para a saúde, foram destacados o sedentarismo e suas possíveis gerações/potencializações de doenças (como obesidade, transtornos de ansiedade, problemas circulatórios, entre outras), visto que tais tecnologias permitem que se resolvam incontáveis demandas cotidianas (pagamento de contas, conversas com família e amigos, inscrições em cursos, estudos, entre outras) sem a necessidade de deslocamentos, usando-se apenas um computador ou um smartphone, por exemplo. Explicitou-se, ainda, uma tendência que têm os usuários das TIC de intencionarem fazer consultas e/ou resolver problemas de saúde através da internet, seja buscando informações em sites de pesquisa, seja insistindo em contatos com profissionais de saúde, exclusivamente, no formato virtual.

Com efeito, há consenso na literatura científica sobre os benefícios de atividades físicas regulares para a saúde, seja em sua dimensão corporal ${ }^{28}$, seja na emocional ${ }^{29-31}$ e em outras, porquanto interligadas. Apesar de se reconhecer a relação das TIC com uma diminuta necessidade de movimentação, intensificada por sua larga utilização em aparelhos que não a exigem, também, já se fazem reais algumas tecnologias que estimulam atividade física, como é o caso do jogo Pokémon Go, já descrito, e de outros jogos, por exemplo de dança, que funcionam como contrapontos ao sedentarismo denunciado.

No que concerne às tentativas de substituição, por algumas TIC, do atendimento de saúde e exames clínicos presenciais, para decisão de conduta terapêutica mais adequada a cada caso, faz-se imprescindível a advertência de que tais tecnologias se destinam a facilitar e complementar esses atendimentos; não a substituí-los ${ }^{32}$. Cabe a divulgação dessa cautela tanto pelos profissionais de saúde, em suas consultas, como nas redes sociais, que também podem ser potencializadoras e facilitadoras de um maior alcance de informações importantes.

Ao se analisarem as possíveis repercussões do blog como ferramenta de educação em saúde, em uma perspectiva interdisciplinar, é preciso mencionar os diversos aspectos positivos. Primeiramente, o fato de o blog constituir um espaço que possibilita a utilização de vários recursos educativos, tais como vídeos, imagens, charges, hiperlinks e textos. Caracteriza-se, portanto, por um hibridismo tecnológico ${ }^{20} \mathrm{e}$ permite, com ele, formas variadas de construção de conhecimentos desejáveis, o que poderá atender aos diferentes estilos de aprendizagen $\mathbf{s}^{19}$.

Ao se constituir um espaço virtual, potente na mediação de processos de educação a distância, cumprindo atividade estabelecida no mestrado Ensino na Saúde, o blog concretizou princípios dessa modalidade educativa, tais como flexibilidade, autonomia, adaptação, interatividade e rompimento da barreira tempo 
e espaço no acesso à informação, posto que a experiência obteve acessos de visitantes de cidades distintas, em todos os horários do dia.

Registra-se também a criação de um ambiente cooperativo de aprendizagem virtual, com diálogos interdisciplinares, que potencializou a construção de saberes e o compartilhamento de experiências sobre práticas de saúde mediadas pelas tecnologias digitais. Cabe frisar, além disso, o potencial do uso pedagógico das TIC na construção de processos educacionais, conferindo racionalidade instrumental no âmbito da formação docente na área de saúde, na pós-graduação stricto sensu. Por fim, a experiência beneficiou a comunidade, uma vez que se disponibilizou material educativo de qualidade, que se desencadearam processos de interação em ambiente virtual, ampliando-se a compreensão de saberes e práticas de saúde. Dessa forma, o blog contribuiu para o cumprimento do indispensável compromisso social das instituições de ensino superior.

Como aspecto negativo, observou-se a dificuldade relatada/demonstrada por alguns visitantes no manuseio do blog, o que ainda é uma realidade comum quando se leva em consideração o uso das TIC em processos educativos, e é considerado um desafio para metodologias de ensino-aprendizagem inovadoras, integradas e exitosas.

A despeito disso, frente à variedade de fatores positivos da experiência suprarrelatados, entende-se que a relação da educação em saúde com as TIC e destas com a interdisciplinaridade faz diferença nos processos de ensino-aprendizagem na atualidade, o que convida a um investimento específico nesses aspectos nas formações profissionais voltadas para a saúde ${ }^{33-34} \mathrm{e}$ nas ações educativas com as comunidades.

Ante o exposto, reflete-se sobre as razões que concorrem para aproveitamento ainda reduzido das TIC virtuais nos cenários educacionais, uma vez que já se configuram a existência e o manuseio, cada vez mais comuns, de tecnologias avançadas ${ }^{35}$ no cotidiano da modernidade líquida de Bauman ${ }^{23}$, mesmo que o acesso a elas ainda não seja a contento em se tratando dos diversos grupos sociais.

Não obstante, o acesso já democratizado, mas, por ora, insuficiente e não inclusivo para todos, apenas convida à ressalva de que a funcionalidade e o potencial das TIC, assim como de qualquer tecnologia educacional, no sentido de contribuir com as dinâmicas de ensino-aprendizagem, precisam responder ao contexto em que serão utilizadas e para quem serão utilizadas ${ }^{10}$.

Cumpre salientar, ademais, a diferença entre a utilização dessas tecnologias nas ações educativas, mas ainda arraigadas a uma metodologia de ensino tradicional, e a sua exploração com método de ensino inovador, ativo, facilitador de autonomia no processo de aprendizagem e de cuidados com a saúde, fomentador de comportamentos cidadãos, críticos e transformadores das realidades sociais. Indubitavelmente, é esse último uso desafiador que se almeja como contribuição das TIC à educação em saúde e à interdisciplinaridade, e a experiência educacional aqui descrita pôde se aproximar do seu potencial de viabilização.

A experiência revela, ainda, em consonância com Amem e Nunes ${ }^{4}$, o valor de uma formação integrada e interdisciplinar, facilitada pelas TIC, no intuito de que os especialistas possam compreender e se preparar para cooperar com outros, tanto nas ciências da saúde, como nas ciências exatas, nas humanas e em quaisquer outras, efetivando propostas interdisciplinares para entender a totalidade complexa do mundo, com seus variados objetos e respectivas significações advindas das interações, e, nela, intervir de modo mais problematizador e resolutivo.

Finalmente, uma vez que a sociedade contemporânea é considerada tecnológica, com um uso cada vez mais massificado das TIC, é pela educação, em seu papel supracitado, que essa utilização pode ser analisada criticamente e, como produto dessa análise, explorada de forma a intervir responsavelmente neste mundo e colaborar com os seus sujeitos. Mostra-se, então, indispensável que essas tecnologias adentrem nos cenários educacionais, nos serviços de saúde, tanto para discussões como para usos potencializadores do processo de ensino-aprendizagem, a fim de que, com elas e por elas, seja possível uma migração dos corpos adoecidos, disciplinados, despidos de força e conscientização, principalmente, no século XIX ${ }^{36}$, a sujeitos 
integrais, que pensam este mundo de TIC. Ou seja, não o ignoram, nem a ele se sujeitam, passivamente, portanto, mas, nele, agem, desconstruindo as tecnologias da informação e da comunicação como poderes aprisionadores e valendo-se delas como formas de resistência, para melhorar a sua saúde e, com elas, o entorno. Segundo Foucault ${ }^{36}$, onde há poder, há resistência; então, que as TIC, na educação em saúde e por ela, de modo interdisciplinar, possam ser validadas em sua face de contribuição resistente!

\section{Considerações finais}

As TIC podem enriquecer as dinâmicas de ensino-aprendizagem de muitas maneiras, por consistirem em veículo, processamento e trocas de informações, movimentos essenciais nessa relação, de modo mais célere e integrador, visto que rompem com barreiras geográficas e de tempo.

Seu potencial de integração entre espaços, tempos, instituições, profissionais e usuários de saúde, ciências e saberes variados é capaz de responder eficientemente à sociedade atual, cada vez mais tecnológica, que demanda sujeitos capazes de refletir e agir responsavelmente sobre seus processos de saúde-doença, e profissionais aptos à flexibilidade, ao trabalho em equipe, à construção do conhecimento de forma diferente e a atuar, cooperativamente, em um mundo globalizado, cuja circulação de informações é, praticamente, imediata.

Assim, é preciso descontinuar qualquer visão dicotômica ou fragmentada que reste de educação e trabalho, já que ambos precisam se contextualizar em um mundo que cresce em interação mediada pelas TIC.

É compreensível que processos de mudança necessitem de tempo para sedimentar seus resultados. Portanto, embora demonstrados os seus potenciais, o caminho em direção à interdisciplinaridade e a práticas de educação em saúde com metodologias não-convencionais de ensino é gradativo e necessita de investimentos em gestor profissional de tempo e financeiro.

Igualmente relevante, o uso das TIC com finalidade educativa em prol da comunidade, para a qual, ricamente, elas podem contribuir, como descrito neste artigo, precisa ser estimulado, abordado e orientado nos contextos de ensino-aprendizagem.

Considera-se, por conseguinte, no cenário atual, que a habilidade dos profissionais da área de saúde para a apropriação e utilização das TIC como ferramentas para mediar processos de ensino é um diferencial, uma vez que são também educadores em suas práticas de promoção, prevenção e recuperação da saúde. Neste sentido, é imprescindível repensar sobre as formações acadêmicas.

Aposta-se nessa alternativa para a produção de uma educação em saúde problematizadora, integrada e contextualizada sociocultural, econômica e politicamente e, após esta experiência, especificamente, para se produzir essa educação em saúde na perspectiva interdisciplinar, com fomentação da autonomia de cuidado através de TIC virtuais, como um blog, de livre acesso à comunidade.

\section{Referências}

1. Silva MG. Informática terminologia: Microsoft Windows 8, Internet, Segurança, Microsoft Office Word 2013, Microsoft Office Excel 2013, Microsoft Office Power Point 2013, Microsoft Office Access 2013. São Paulo: Érica; 2013.

2. Feuerwerker LCM. Impulsionando o movimento de mudanças na formação dos profissionais de saúde. São Paulo: Papirus; 2003.

3. Darling-Hammond L, Wilhoit G, Pittenger L. Accountability for college and career readiness: developing a new paradigm. Educ Policy Anal Arc [Internet]. 2014 [cited 2016 Oct. 4];22(86):1-38. doi: http://dx.doi. org/10.14507/epaa.v22n86.2014

4. Amem BMV, Nunes LC. Tecnologias de informação e comunicação: contribuições para o processo interdisciplinar no ensino superior. R Bras Educ Med [Internet]. 2006 [citado em 2018 maio 15];29(30):171-80. doi: http://dx.doi.org/10.1590/S0100-55022006000300008 
5. Reis ZSN, Melo MCB, Corrêa EJ, Pereira AK, Santos DB, Alves HJ. Tecnologias digitais para o ensino em saúde: relato de experiências e a convergência para o projeto AVAS21. R Saúde Dig Tec Edu [Internet]. 2016 [citado em 2016 dez. 12];1(1):69-76. Disponível em: https://goo.gl/Zkgh94

6. Feijão AR, Galvão MTG. Ações de educação em saúde na atenção primária: revelando métodos, técnicas e bases teóricas. R Rene [Internet]. 2007 [citado em 2017 fev. 8];8(2):41-9. Disponível em: http:// www.periodicos.ufc.br/index.php/rene/article/view/5296/3895

7. Palacio MAV, Struchiner M. Análise do uso de recursos de interação, colaboração e autoria em um ambiente virtual de aprendizagem para o ensino superior na área da saúde. Ci Edu (Bauru) [Internet]. 2016 [citado em 2016 out. 19];22(2):413-30. doi: http://dx.doi.org/10.1590/1516-731320160020009

8. Lobo ASM, Maia LCG. O uso das TICs como ferramenta de ensino-aprendizagem no ensino superior. C Geogr [Internet]. 2015 [citado em 2016 out. 18]; 25(44):16-26. Disponível em: http://dx.doi. org/10.5752/p.2318-2962.2015v25n.44p.16

9. Morin E. Ciência com consciência.14 ed. Rio de Janeiro: Bertrand; 2010.

10. Silva VM, Maia LSL. Representações sociais de tecnologia compartilhadas pelos professores e suas relações com a prática pedagógica em função da região em que atuam. Educ R [Internet]. 2015 [citado em 2018 maio 15];16(1):51-66. Disponível em: https://goo.gl/Za8jfd

11. Ceccim RB, Carvalho YM. Ensino da saúde como projeto da integralidade: a educação dos profissionais de saúde no SUS. In: Ceccim RB, Pinheiro R, Mattos RA. Ensinar saúde: a integralidade e o SUS nos cursos de graduação na área da saúde. Rio de Janeiro: UERJ, CEPESC, ABRASCO; 2011:69-92.

12. Almeida MJ, Campos JJB, Turini B, Nicoletto SCS, Pereira LA, Rezende LR, et al. Implantação das Diretrizes Curriculares Nacionais na Graduação em Medicina no Paraná. R Bras Educ Med [Internet]. 2007 [citado em 2018 maio 15];31(2):156-65. doi: http://dx.doi.org/10.1590/S0100-55022007000200006

13. Amoretti R. A educação médica diante das necessidades sociais em saúde. R Bras Educ Med. [Internet]. 2005 [citado em 2018 maio 15];29(2):136-46. Disponível em: https://goo.gl/jkJCij

14. Lampert JB. Currículo da graduação e o contexto da formação do médico. R Bras Educ Med 2001;25(1):7-19.

15. Organização Mundial de Saúde. Constituição da Organização Mundial de Saúde [Internet]. Nova Iorque; 1946 [citado em 2016 ago. 2]. Disponível em: https://goo.gl/NZ8dMp

16. Schwertner SF. Encontros da medicina com a educação infantil: formação para a educação e para a saúde. RECIIS [Internet]. 2017 [citado em 2017 abr. 20];11(1):1-9. Disponível em: https://goo.gl/aExDmT

17. Capra F. O ponto de mutação. 30 reimp. São Paulo: Cultrix; 2014.

18. Severino AJ. Do ensino da filosofia: estratégias interdisciplinares. Educ Ver [Internet]. 2011 [2018 maio 15];12(1):81-96. Disponível em: https://goo.gl/zFX4yb

19. Deaquino CTE. Como aprender: andragogia e as habilidades de aprendizagem. São Paulo: Pearson Prentice Hall; 2007.

20. Beckes $L$, Ratto $C G$. The tribes in the context of the digital technological hybridism: the constitution of the virtual digital acquaintanceship. ETD [Internet]. 2016 [cited 2016 Oct 12];18(3):564-79. Available from: https://goo.gl/xiDepC

21. Vargas FMA, Trindade MCN da, Gouveia GDA, Farias MR. A educação a distância na qualificação de profissionais para o Sistema único de Saúde: metaestudo. Trab Educ Saúde [Internet]. 2016 [citado em 2018 maio 15];14(3):849-70. doi: http://dx.doi.org/10.1590/1981-7746-sol00018

22. Bardin L. Análise de conteúdo. 6. ed. rev. e ampl. Lisboa: 70; 2011.

23. Bauman Z. Vida em fragmentos: sobre a ética pós-moderna. Rio de Janeiro: Zahar; 2011.

24. Wen CL. Telemedicina e telessaúde: aplicação de tecnologia para promover educação interativa e formação de rede de interconsulta profissional em saúde. In: Trindade MAB, organizador. As tecnologias da informação e comunicação (TIC) no desenvolvimento profissional de trabalhadores do SUS. São Paulo: Instituto de Saúde; 2011:95-112. (Temas em Saúde Coletiva, 12).

25. Oliveira VAD, Brasil LSB. Repensando a educação permanente em saúde na sociedade da informação: a experiência da Universidade Aberta do Sistema Único de Saúde In: Trindade MAB, organizador. As tecnologias da informação e comunicação (TIC) no desenvolvimento profissional de trabalhadores do SUS. São Paulo: Instituto de Saúde; 2011:191-217. (Temas em Saúde Coletiva, 12). 
26. Seixas PHD. Considerações a respeito das possibilidades e oportunidades de se incorporar ações de EaD no Sistema de Educação Permanente para o SUS-SP. In: Trindade MAB, organizador. As tecnologias da informação e comunicação (TIC) no desenvolvimento profissional de trabalhadores do SUS. São Paulo: Instituto de Saúde; 2011:245-63. (Temas em Saúde Coletiva, 12).

27. Guimarães MCS, Silva CH, Santana RAL. Uma abordagem de educação para saúde a partir da informação científica e tecnológica. Rev Eletron Comun Inf Inov Saude [Internet]. 2012 [citado em 2016 dez. 20];6(2):1-7. Disponível em: https://goo.gl/B3jxSa

28. Silva RS, Silva I, Silva RA, Souza L, Tomasi E. Atividade física e qualidade de vida. C Saúde Coletiva [Internet]. 2010 [citado em 2016 dez. 11];15(1):115-20. doi: http://dx.doi.org/10.1590/S141381232010000100017

29. Oliveira FA, Pirajá WC, Silva AP, Primo CPF. Benefícios da prática de atividade física sistematizada no lazer de idosos: algumas considerações. Licere [Internet]. 2015 [citado em 2016 ago. 6];18(2):262-304. Disponível em: https://seer.ufmg.br/index.php/licere/article/view/1052

30. Vargas L, Lara MVS, Mello-Carpes PB. Influência da diabetes e a prática de exercício físico e atividades cognitivas e recreativas sobre a função cognitiva e emotividade em grupos de terceira idade. $R$ Bras Geriatr Gerontol. 2014 [citado em 2018 maio 15];17(4):867-78. Disponível em: http://www.scielo.br/ pdf/rbgg/v17n4/1809-9823-rbgg-17-04-00867.pdf

31. Godoy RF. Benefícios do exercício físico sobre a área emocional. Movimento: R Esc Educ Física UFRS [Internet]. 2002 [2018 maio 15];8(2):7-15. Disponível em: http://www.seer.ufrgs.br/index.php/ Movimento/article/view/2639/1265

32. Dixon N. Common knowledge: how companies thrive by sharing what they know. Harvard: Harvard Business School Press; 2000.

33. Siqueira GC. A invasão das tecnologias de informação e comunicação nas escolas e o diálogo necessário. ETD [Internet]. 2016 [citado em 2016 dez. 12];18(1):122-35. Disponível em: http://periodicos.sbu. unicamp.br/ojs/index.php/etd/article/view/8637541/12230

34. Torres AL, Mota MM, Ferreira HS, Ferreira AF, Darido SC. As tecnologias da informação e comunicação e a educação física escolar: a realidade de professores da rede pública municipal de Fortaleza. ETD [Internet]. 2016 [citado em 2016 dez. 20];18(1):198-214. Disponível em: http://periodicos.sbu.unicamp. br/ojs/index.php/etd/article/view/8640601/12234

35. Andrade Netto ML, Loyolla W. As tecnologias da informação e comunicação na formação de trabalhadores. In: Trindade MAB, organizador. As tecnologias da informação e comunicação (TIC) no desenvolvimento profissional de trabalhadores do SUS. São Paulo: Instituto de Saúde; 2011:177-90. (Temas em Saúde Coletiva, 12).

36. Foucault M. História da sexualidade. A vontade de saber. 13 ed. Rio de Janeiro: Graal; 2009. 